\title{
Avaliação da atividade anti-séptica de extrato seco de Stryphnodendron adstringens (Mart.) Coville e de preparação cosmética contendo este extrato
}

\author{
Tatiana M. Souza ${ }^{1 *}$, Raquel R.D. Moreira ${ }^{2}$, Rosemeire C.L.R. Pietro ${ }^{3,4}$, Vera L.B. Isaac ${ }^{1}$ \\ ${ }^{1}$ LaCos (Laboratório de Cosmetologia); Faculdade de Ciências Farmacêuticas, Universidade Estadual Paulista \\ "Júlio de Mesquita Filho", Rodovia Araraquara-Jaú, 14801-902, SP, Brasil, \\ ${ }^{2}$ Laboratório de Farmacognosia, Faculdade de Ciências Farmacêuticas, Universidade Estadual Paulista "Júlio de \\ Mesquita Filho", Rodovia Araraquara-Jaú, 14801-902, SP, Brasil, \\ ${ }^{3}$ Laboratório de Biotecnologia Farmacêutica, Faculdade de Ciências Farmacêuticas, Universidade Estadual \\ Paulista "Júlio de Mesquita Filho", Rodovia Araraquara-Jaú, 14801-902, SP, Brasil, \\ ${ }^{4}$ Curso de Ciências Farmacêuticas, Universidade de Ribeirão Preto, UNAERP, Avenida Costábile Romano, 2201, \\ 14096-380, Ribeirão Preto, SP, Brasil
}

\begin{abstract}
RESUMO: As espécies pertencentes ao gênero Stryphnodendron são conhecidas como "barbatimão" e são nativas do cerrado brasileiro. Possuem taninos como metabólitos secundários primordiais de suas cascas apresentando, entre outras, atividade antimicrobiana e cicatrizante. A concentração bactericida mínima (CBM) do extrato seco das cascas de Stryphnodendron adstringens frente a duas bactérias Gram-positivas e uma bactéria Gram-negativa foi determinada pela técnica de diluição em tubos. A atividade antimicrobiana do extrato seco e a atividade antiséptica de sabonete líquido contendo o extrato seco foram avaliadas pelo método de difusão em ágar. O extrato apresentou valores de concentração bactericida mínima de $50 \mathrm{mg} / \mathrm{mL}$ frente a Staphylococcus aureus e $75 \mathrm{mg} / \mathrm{mL}$ contra Staphylococcus epidermidis e Escherichia coli e no teste de difusão em ágar, $S$. aureus apresentou maior sensibilidade ao extrato seco que as outras bactérias. $\mathrm{O}$ sabonete líquido mostrou maior eficiência na atividade anti-séptica contra as bactérias testadas na concentração de $100 \mathrm{mg}$ de extrato/mL de sabonete.
\end{abstract}

Unitermos: Stryphnodendron adstringens, Leguminosae, atividade anti-séptica, concentração bactericida mínima, taninos.

\begin{abstract}
Antiseptic activity evaluation of the dry extract from Stryphnodendron adstringens (Mart.) Coville and cosmetic preparation". The species of the genus Stryphnodendron are known as "barbatimão" and are native from Brazilian "cerrado". They present tannins as main secondary metabolites of their barks and show antimicrobial and cicatrisation activity among others. The minimum bactericidal concentration (MBC) of the dry extract from the barks of Stryphnodendron adstringens against two Gram-positive and one Gram-negative bacteria was done using methodology of broth dilution in tubes. The antimicrobial activity of the dry extract and the antiseptic activity of the liquid soap containing that dry extract were evaluated by agar difusion method. For the extract were obtained the minimum bactericidal concentration values of $50 \mathrm{mg} / \mathrm{mL}$ against Staphylococcus aureus and $75 \mathrm{mg} / \mathrm{mL}$ against Staphylococcus epidermidis and Escherichia coli and by agar difusion, S. aureus showed more sensibility to the dry extract than the other bacteria. The liquid soap showed efficiency in the antiseptic activity against the bacteria studied at the concentration of $100 \mathrm{mg}$ of extract $/ \mathrm{mL}$ of soap.
\end{abstract}

Keywords: Stryphnodendron adstringens, Leguminosae, antiseptic activity, minimum bactericidal concentration, tannins.

\section{INTRODUÇÃO}

A humanidade depende, diretamente, da biodiversidade para extrair ou produzir alimentos, cosméticos, novos materiais e processos (John, 2002). O uso de produtos naturais com propriedades terapêuticas é tão antigo quanto a civilização humana e, por um longo tempo, produtos minerais, animais e vegetais foram a principal fonte de fármacos (Esquenazi et al., 2002).
Stryphnodendron adstringens (Mart.) Coville, pertencente à família Leguminosae-Mimosoidae, é uma árvore do cerrado brasileiro conhecida popularmente como "barbatimão". Na medicina caseira, o decocto das cascas desta planta é amplamente empregado na maioria das regiões do Brasil no tratamento da leucorréia, hemorragias, diarréia, hemorróidas, para limpeza de ferimentos e na forma de gotas contra conjuntivite (Nunes et al., 2003; Macedo; Ferreira et al., 2004). Estas 
atividades devem-se à riqueza em taninos presentes na casca dessa planta (Lorenzi, 2000; Lorenzi; Matos, 2002; Santos et al., 2006). Segundo Toledo (2002) o extrato obtido das cascas de Stryphnodendron adstringens demonstra atividade antimicrobiana contra Pseudomonas aeruginosa, Staphylococcus aureus e Bacillus subtilis. Também encontra-se descrito na literatura outras atividades para esta espécie como tripanocida (HerzogSoares et al., 2002) e antiinflamatória (Falcão et al., 2005). A sua grande utilização levou à inclusão na primeira, segunda e quarta edição da Farmacopéia Brasileira (Brandão et al., 2006).

O uso de plantas pode representar uma alternativa de substituição aos anti-sépticos e desinfetantes sintéticos convencionais, visando evitar o desenvolvimento de resistência bacteriana a estes compostos, uma vez que metabólitos vegetais atuam por mecanismos variados (Barbour et al., 2004; Monthana; Lindequist, 2005).

O objetivo deste trabalho foi determinar a concentração bactericida mínima do extrato seco das cascas de $S$. adstringens contra as bactérias Staphylococcus aureus, Staphylococcus epidermidis e Escherichia coli, bem como avaliar a atividade antiséptica de um sabonete líquido desenvolvido a partir deste extrato.

\section{MATERIAL E MÉTODOS}

\section{Material vegetal}

As cascas secas e pulverizadas de Stryphnodendron adstringens (Mart.) Coville foram adquiridas do lote 027 da empresa Ely Martins Ltda., situada na cidade de Ribeirão Preto, São Paulo, Brasil, a qual forneceu o laudo de controle de qualidade que não apresentou objeções para a utilização da droga.

Foram realizadas reações de precipitação e formação de coloração para caracterização de compostos das diferentes classes de metabólitos secundários, segundo Costa (1994). Os testes para taninos e saponinas foram feitos com o decocto da droga. Para taninos procedeu-se a precipitação por adição de solução de gelatina $2 \%$ em meio ácido. Para saponinas foi realizado o teste de formação de espuma duradoura após 20 minutos de agitação vertical do decocto. Para flavonóides, procedeuse a reação de Shinoda, na qual a droga foi previamente tratada com éter de petróleo e metanol e suspendida em etanol, sendo adicionado magnésio metálico em meio ácido. Reação positiva apresenta liberação de gás (hidrogênio) e coloração vermelha.

Como controle de qualidade da droga foram realizados os testes de medida do $\mathrm{pH}$ da infusão da droga em concentração de 1\% utilizando pH-metro Micronal B374 e do teor de umidade colocando $4 \mathrm{~g}$ da droga em balança analítica com infravermelho em temperatura de $115^{\circ} \mathrm{C}$, sendo as leituras feitas a cada hora até que o peso não variasse mais que $0,25 \%$. Todos os testes de controle de qualidade foram feitos em triplicata.

Obtenção do extrato seco das cascas de Stryphnodendron adstringens

O extrato seco de $S$. adstringens foi obtido por percolação das cascas utilizando-se etanol 50\% como solvente. Em seguida foi concentrado em evaporador rotatório sob pressão reduzida e, posteriormente, liofilizado.

A constituição qualitativa do extrato foi analisada por Cromatografia em Camada Delgada Comparativa (CCDC) utilizando catequina como padrão. Extrato e padrão foram suspensos em metanol, aplicados em sílica gel $60 \mathrm{~F}_{254}$ Merck $^{\circledR}$, eluídos em sistema solvente constituído pela fase orgânica de clorofórmio: metanol:n-propanol:água $(5: 6: 1: 4 ; \mathrm{v} / \mathrm{v})$ e revelados com cloreto férrico $2 \%$ em metanol. A coloração azul escura indica a presença de taninos (Wagner et al., 1984). Já a constituição quantitativa do extrato foi analisada pelo método de determinação do teor de fenóis totais (AOAC, 1984) utilizando solução $0,1 \mathrm{mg} / \mathrm{mL}$ de ácido tânico para construção da curva analítica e solução $0,1 \mathrm{mg} / \mathrm{mL}$ de extrato. A alíquotas de 0,2 a $0,7 \mathrm{~mL}$ destas soluções foram adicionados $0,5 \mathrm{~mL}$ do reagente Folin-Denis e 1 $\mathrm{mL}$ de $\mathrm{Na}_{2} \mathrm{CO}_{3} 35 \%$, completando para $10 \mathrm{~mL}$ com água. A leitura foi feita em espectrofotômetro Shimadzu UV1603 após 30 minutos de reação em $730 \mathrm{~nm}$. Utilizou-se como branco uma solução de $0,5 \mathrm{~mL}$ de Folin-Denis e 1 $\mathrm{ml}$ de $\mathrm{Na}_{2} \mathrm{CO}_{3}$ em $10 \mathrm{~mL}$ de volume.

\section{Cepas utilizadas}

Para os testes de atividade antimicrobiana foram utilizados as cepas de duas bactérias Gram-positivas, Staphylococcus aureus ATCC 25923 e Staphylococcus epidermidis ATCC 12228 e, uma Gram-negativa, Escherichia coli ATCC 10536.

\section{Determinação da concentração bactericida mínima do extrato (CBM)}

A concentração bactericida mínima do extrato seco de $S$. adstringens foi determinada através da metodologia de diluição em tubos. Uma colônia de cada cepa utilizada foi inoculada em caldo de BHI ("brain and heart infusion") e incubada a $37^{\circ} \mathrm{C}$ durante 24 horas. A partir deste inóculo, foi ajustada a turvação até $0,5 \mathrm{da}$ Escala de McFarland e, em seguida, as bactérias foram diluídas 1:100. Foi preparada uma solução estoque do extrato seco de $S$. adstringens por dissolução em dimetilsulfóxido (DMSO) e em BHI. Nos testes de atividade antimicrobiana as concentrações finais do extrato foram 100, 75, 50 e $25 \mathrm{mg} / \mathrm{mL}$, aos quais foram adicionadas as bactérias convenientemente diluídas. Após incubação por $24 \mathrm{~h}$ a $37^{\circ} \mathrm{C}$, uma amostra de cada tubo foi transferida para placas de Petri com meio sólido de Müeller Hinton, sendo incubadas por $24 \mathrm{~h}$ a $37{ }^{\circ} \mathrm{C}$ 
Tabela 1. Determinação da concentração bactericida mínima (CBM) do extrato seco de S. adstringens.

\begin{tabular}{l|cccc}
\hline \multirow{2}{*}{ Microrganismos } & \multicolumn{4}{|c}{ Concentração do extrato seco de $S$. adstringens } \\
\cline { 2 - 5 } & $100 \mathrm{mg} / \mathrm{mL}$ & $75 \mathrm{mg} / \mathrm{mL}$ & $50 \mathrm{mg} / \mathrm{mL}$ & $25 \mathrm{mg} / \mathrm{mL}$ \\
\hline S. aureus & - & - & - & + \\
S. epidermidis & - & - & + & + \\
E. coli & - & - & + & + \\
\hline
\end{tabular}

- ausência de crescimento bacteriano, + crescimento bacteriano.

Tabela 2. Halos de inibição de diferentes concentrações do extrato seco de $S$. adstringens contra $S$. aureus, $S$. epidermidis e E. coli.

\begin{tabular}{l|ccc}
\hline Amostras & S. aureus & S. epidermidis & E. coli \\
\hline Ampicilina & $16,0 \pm 0,0^{\mathrm{a}}$ & $15,0 \pm 0,7$ & $15,0 \pm 0,7$ \\
$200 \mathrm{mg} / \mathrm{mL}$ & $21,0 \pm 0,0$ & $18,5 \pm 0,7$ & $13,0 \pm 0,0$ \\
$100 \mathrm{mg} / \mathrm{mL}$ & $19,0 \pm 1,4$ & $18,0 \pm 0,0$ & $11,5 \pm 0,7$ \\
$75 \mathrm{mg} / \mathrm{mL}$ & $18,0 \pm 2,8$ & $17,5 \pm 0,7$ & $11,5 \pm 0,7$ \\
$50 \mathrm{mg} / \mathrm{mL}$ & $18,0 \pm 2,8$ & $16,0 \pm 0,0$ & $11,5 \pm 0,7$ \\
$25 \mathrm{mg} / \mathrm{mL}$ & $15,5 \pm 0,7$ & $14,0 \pm 0,0$ & $10,5 \pm 0,7$ \\
\hline
\end{tabular}

a) os valores representam a média e o desvio-padrão de triplicatas dos halos de inibição expressos em $\mathrm{mm}$.

Tabela 3. Halos de inibição de diferentes concentrações do sabonete sem conservante contra S. aureus, S. epidermidis e E. coli.

\begin{tabular}{l|ccc}
\hline Amostras & S. aureus & S. epidermidis & E. coli \\
\hline Ampicilina & $15,0 \pm 0,7^{\mathrm{a}}$ & $15,0 \pm 0,7$ & $15,0 \pm 0,7$ \\
$200 \mathrm{mg} / \mathrm{mL}$ & $14,0 \pm 0,7$ & $14,0 \pm 1,4$ & $11,0 \pm 1,4$ \\
$100 \mathrm{mg} / \mathrm{mL}$ & $13,0 \pm 1,4$ & $13,0 \pm 0,7$ & $10,0 \pm 0,0$ \\
$75 \mathrm{mg} / \mathrm{mL}$ & $10,0 \pm 0,0$ & $10,0 \pm 0,7$ & $9,0 \pm 0,7$ \\
$50 \mathrm{mg} / \mathrm{mL}$ & $10,0 \pm 0,0$ & $9,0 \pm 0,7$ & $9,0 \pm 0,0$ \\
\hline
\end{tabular}

a) os valores representam a média e o desvio-padrão de triplicatas dos halos de inibição expressos em mm.

para posterior verificação de presença ou ausência de crescimento bacteriano. Todos os testes foram feitos em triplicata, sendo conduzidos, simultaneamente, testes controle com as bactérias, com o solvente DMSO e com o extrato.

\section{Teste de difusão em ágar}

A atividade antimicrobiana do extrato seco também foi avaliada pelo método de difusão em ágar através de orifícios de $6 \mathrm{~mm}$ de diâmetro feitos no próprio meio de cultura Müeller Hinton previamente inoculado com as bactérias. A formação do halo de inibição foi avaliada após adição de $50 \mu \mathrm{L}$ de amostra de uma solução de ampicilina (concentração de $0,05 \mathrm{mg} / \mathrm{mL}$ ) e adição de $50 \mu \mathrm{L}$ de solução do extrato em DMSO:BHI $(1: 1 \mathrm{v} / \mathrm{v})$ obtendo concentrações de extrato em cada orifício de $200 \mathrm{mg} / \mathrm{mL}, 100 \mathrm{mg} / \mathrm{mL}, 75 \mathrm{mg} / \mathrm{mL}, 50 \mathrm{mg} / \mathrm{mL}$ e $25 \mathrm{mg} /$ $\mathrm{mL}$.

Pela mesma metodologia, foi realizada a avaliação da atividade anti-séptica do sabonete líquido contendo o extrato seco de cascas de $S$. adstringens, sendo que a formação do halo de inibição foi avaliada após adição de $50 \mu \mathrm{L}$ de amostra de uma solução de ampicilina (concentração de $0,05 \mathrm{mg} / \mathrm{mL}$ ) e adição de 50 $\mu \mathrm{L}$ do sabonete sem o extrato e do sabonete contendo o extrato nas concentrações de $200 \mathrm{mg} / \mathrm{mL}, 100 \mathrm{mg} / \mathrm{mL}, 75$ $\mathrm{mg} / \mathrm{mL}$ e $50 \mathrm{mg} / \mathrm{mL}$. O sabonete utilizado nos testes não continha conservante.

Todas as placas foram incubadas a $37{ }^{\circ} \mathrm{C}$ por $24 \mathrm{~h}$. Todos os testes foram realizados em duplicata.

\section{Preparo do sabonete líquido}

As matérias-primas utilizadas para formular o sabonete líquido foram: lauriletersulfato de sódio, cocoanfocarboxiglicinato, laurilpoliglicosídeo, decilpoliglicosídeo, dietanolamida de ácido graxo de coco, ácido cítrico (solução aquosa 10\%), extrato seco de S. adstringens e água destilada.

O sabonete líquido foi manipulado pela dispersão dos tensoativos, do conservante e água. Em seguida, foi acrescentada a solução aquosa da ácido cítrico para correção até pH 6, valor compatível com a pele. A seguir, o extrato seco de $S$. adstringens foi incorporado em quantidade suficiente para se obter as concentrações: $50,75,100$ e $200 \mathrm{mg} / \mathrm{mL}$.

\section{Testes de estabilidade da formulação}

Foram avaliados parâmetros organolépticos e físico-químicos do sabonete com e sem o extrato seco 
de $S$. adstringens através de metodologia de avaliação da estabilidade preliminar apresentada pelo Guia de Estabilidade de Produtos Cosméticos (ANVISA, 2004). Desta forma, os parâmetros organolépticos avaliados foram aspecto, cor e odor e foram realizados testes de medida do $\mathrm{pH}$ de uma solução aquosa do sabonete a $10 \%$, medida da densidade em picnômetro de $5 \mathrm{~mL}$ e medida da viscosidade em viscosímetro a $20 \mathrm{rpm}$ como avaliação dos parâmetros físico-químicos.

\section{RESULTADOS E DISCUSSÃO}

A coloração do extrato impediu a visualização de presença de turvação nos tubos, por isso, a inibição do crescimento bacteriano proporcionada pelas diferentes concentrações foi avaliada pela concentração bactericida mínima, indicada pela presença ou ausência de crescimento bacteriano nas placas de Petri. Os valores de concentração bactericida mínima para o extrato seco de $S$. adstringens podem ser observados na Tabela 1 .

As concentrações de extrato em que não houve crescimento bacteriano foram menores frente a $S$. aureus, enquanto em relação a $S$. epidermidis e $E$. coli os valores foram coincidentes e superiores. Os valores relativos à média dos halos de inibição obtidos na avaliação da atividade antimicrobiana do extrato seco de $S$. adstringens através do método de difusão em ágar podem ser observados na Tabela 2.

Desta forma, foi verificado que $E$. coli mostrouse menos sensível às concentrações-teste utilizadas do que as bactérias $S$. aureus e $S$. epidermidis, sendo que os valores de halo de inibição obtidos para estas duas bactérias foram próximos.

A média dos valores dos halos de inibição e valores de desvio-padrão, em relação às bactérias testadas, da solução controle de ampicilina e das amostras de sabonete com o extrato seco de $S$. adstringens, em diferentes concentrações, estão descritos na Tabela 3 .

Assim, foi possível observar que os valores dos halos de inibição entre $S$. aureus e $S$. epidermidis são muito próximos; entretanto, a bactéria $E$. coli mostrou-se menos sensível em relação ao sabonete com extrato seco de $S$. adstringens. Os maiores halos de inibição foram obtidos com as maiores concentrações do extrato. Notouse que, na concentração de $100 \mathrm{mg}$ do extrato/mL de sabonete obteve-se atividade anti-séptica para $S$. aureus, S. epidermidis e E. coli atingindo níveis de 93,33\%, $86,66 \%$ e $73,33 \%$ de inibição quando comparado à ampicilina, respectivamente.

Os resultados obtidos em relação à avaliação da atividade anti-séptica do sabonete líquido contendo o extrato seco das cascas de $S$. adstringens, demonstram que o sabonete sem o extrato mostrou redução do crescimento das bactérias, no entanto, sem formação nítida de halo de inibição.

A triagem fitoquímica realizada para caracterização de classes de metabólitos secundários

17(1): Jan./Mar. 2007 indicou a presença de taninos nas cascas de $S$. adstringens, mas não indicou a presença de saponinas e flavonóides. Como controle de qualidade da droga foram realizados testes de determinação de $\mathrm{pH}(6,25)$ e o teor de $8,18 \%$ indicou que a umidade estava dentro da faixa permitida (Farmacopéia Brasileira, 1988). Por fim, pela metodologia utilizada para obtenção do extrato seco, o rendimento foi de aproximadamente $40 \%$.

A cromatografia em camada delgada demonstrou que o extrato seco das cascas de $S$. adstringens possui taninos, uma vez que as manchas ( $\mathrm{Rf}$ zero e 0,47$)$ da amostra do extrato apresentadas após a revelação da cromatografia tinham a mesma coloração da mancha do padrão catequina $(\operatorname{Rf} 0,45)$, não apresentando nenhum outro derivado de fenol. O teor de fenóis totais foi utilizado, portanto, como forma de padronizar o extrato seco obtido apresentando um teor de 17,45 \pm $0,50 \%$ de fenóis totais em relação ao extrato. Os taninos formam complexos com proteínas através de pontes de hidrogênio, interações hidrofóbicas e por formação de ligação covalente, sendo capazes de inativar adesinas e enzimas bacterianas, além de formarem complexo com polissacarídeos (Cowan, 1999). Possivelmente, as propriedades antibacteriana do extrato e anti-séptica do sabonete foram proporcionadas pela presença de metabólitos secundários da classe dos taninos.

A concentração do extrato seco de $S$. adstringens equivalente a $75 \mathrm{mg} / \mathrm{mL}$ foi suficiente para inibir o crescimento de $S$. epidermidis e $E$. coli, enquanto que para $S$. aureus a concentração foi de $50 \mathrm{mg} / \mathrm{mL}$. Toledo (2002) realizou um estudo de determinação da concentração inibitória mínima de diversas subfrações da fração acetato de etila de um extrato acetona:água (7:3) das cascas de $S$. adstringens contra $S$. aureus através do método de diluição em microplaca. Uma vez que Toledo utilizou amostras purificadas (teor de fenóis não descrito) e uma metodologia mais sensível, os valores de concentração inibitória mínima atingiram um máximo de $1 \mathrm{mg} / \mathrm{mL}$, segundo a subfração estudada.

Observou-se que o extrato seco, quando incorporado à formulação de sabonete líquido, apresentou atividade anti-séptica mais efetiva quando na concentração de $100 \mathrm{mg} / \mathrm{mL}$, sendo maior que a concentração bactericida mínima obtida para o extrato seco isolado.

Pela avaliação da estabilidade, observouse que a incorporação do extrato seco alterou alguns dos parâmetros avaliados (não alterando a densidade), aumentando o pH da formulação de 6 para 7 e reduzindo a viscosidade do sabonete em relação à formulação sem o extrato. No entanto, estas alterações não prejudicaram a estabilidade da formulação do sabonete líquido e a adequabilidade desta formulação para seu uso após os 15 dias de teste. Os parâmetros organolépticos não sofreram alterações durante o mesmo período.

A partir da atividade antimicrobiana determinada para o extrato seco de $S$. adstringens, também foi 
verificado que o sabonete líquido incorporado com o referido extrato apresentou atividade anti-séptica, sem alterações significativas de sua estabilidade.

\section{AGRADECIMENTOS}

Apoio técnico: Luciene Regina Araújo e Luís Eduardo dos Santos da Faculdade de Ciências Farmacêuticas - UNESP - Araraquara. Apoio Financeiro: Fundação de Amparo à Pesquisa do Estado de São Paulo (FAPESP) e PADC - FCF - UNESP.

\section{REFERÊNCIAS}

ANVISA - Agência Nacional de Vigilância Sanitária 2004. Séries Temáticas: Cosméticos_Guia de Estabilidade de Produtos Cosméticos, v. I. Disponível em: www. anvisa.gov.br, acessada em setembro de 2004.

AOAC - Association of Official Analytical Chemists. 1984. Official Methods of Analysis of the Association of Chemists. 13 ed. Washington, D.C.: Association of Official Analytical Chemists.

Barbour EK, AL Sharifa M, Sagheriana VK, Habrea AN, Talhouk RS, Talhouk SN 2004. Screening of selected indigenous plants of Lebanon for antimicrobial activity. J Ethnopharmacol 93: 1-7.

Brandão MGL, Cosenza GP, Moreira RA, Monte-Mor RLM 2006. Medicinal plants and other botanical products from the Brazilian Official Pharmacopoeia. Rev Bras Farmacogn 16: 408-420.

Costa AF 1994. Farmacognosia. Lisboa: Fundação Calouste Gulbenkian.

Cowan MM 1999. Plant products as antimicrobial agents. Clin Microbiol Rev 12: 564-582.

Esquenazi D, Wigg MD, Miranda MM, Rodrigues HM, Tostes JB, Rozental S, Silva AJ, Alviano CS 2002. Antimicrobial and antiviral activities of polyphenolics from Cocos nucifera Linn. (Palmae) husk fiber extract. Res Microbiol 153: 647-652.

Falcão HS, Lima IO, Santos VL, Dantas HF, Diniz MFFM, Barbosa-Filho JM, Batista LM 2005. Review of the plants with anti-inflammatory activity studied in Brazil. Rev Bras Farmacogn 15: 381-391.

Farmacopéia Brasileira 1988. 4.Edição, São Paulo: Atheneu.

Herzog-Soares JD, Alves RK, Isac E, Bezerra JCB, Gomes MH, Santos SC, Ferri PH 2002. Atividade tripanocida in vivo de Stryphnodendron adstringens (barbatimão verdadeiro) e Caryocar brasiliensis (pequi). Rev Bras Farmacogn 12(Supl. 1): 1-2.

John L 2004. ONU alerta para destruição da biodiversidade. $O$ Estado de São Paulo, 05 de agosto de 2002. Disponível em: http://www.estadao.com.br/ciencia/noticias/2002/ ago/05/22.htm., acessada em janeiro de 2004.

Lorenzi H 2000. Árvores brasileiras: manual de identificação e cultivo de plantas arbóreas nativas do Brasil. Nova Odessa, SP: Instituto Plantarum.

Lorenzi H, Matos FJA 2002. Plantas medicinais no Brasil: nativas e exóticas. Nova Odessa, SP: Instituto Plantarum.

Macedo M, Ferreira AR 2004. Plantas medicinais usadas para tratamentos dermatológicos, em comunidades da Bacia do Alto Paraguai, Mato Grosso. Rev Bras Farmacogn 14(Supl. 1): 40-44.

Monthana RAA, Lindequist U 2005. Antimicrobial activity of some medicinal plants of the island Soqotra. $J$ Ethnopharmacol 96: 177-181.

Nunes GP, Silva MF, Resende UM, Siqueira JM 2003. Plantas medicinais comercializadas por raizeiros no Centro de Campo Grande, Mato Grosso do Sul. Rev Bras Farmacogn 13: 83-92.

Santos SC, Costa WF, Batista F, Santos LR, Ferri PH, Ferreira HD, Seraphin JC 2006. Seasonal variation in the content of tannins in barks of barbatimão species. Rev Bras Farmacogn 16: 552-556.

Toledo CEM 2002. Estudos anatômico, químico e biológico de cascas e extratos obtidos de barbatimão (Stryphnodendron adstringens (Mart.) Coville, Leguminosae). Araraquara, 115p. Dissertação de Mestrado - Faculdade de Ciências Farmacêuticas, Universidade Estadual Paulista.

Wagner H, Bladt S, Zgainski EM 1984. Plant drug analysis: a Thin Layer chromatography atlas. Berlin: Springer. 